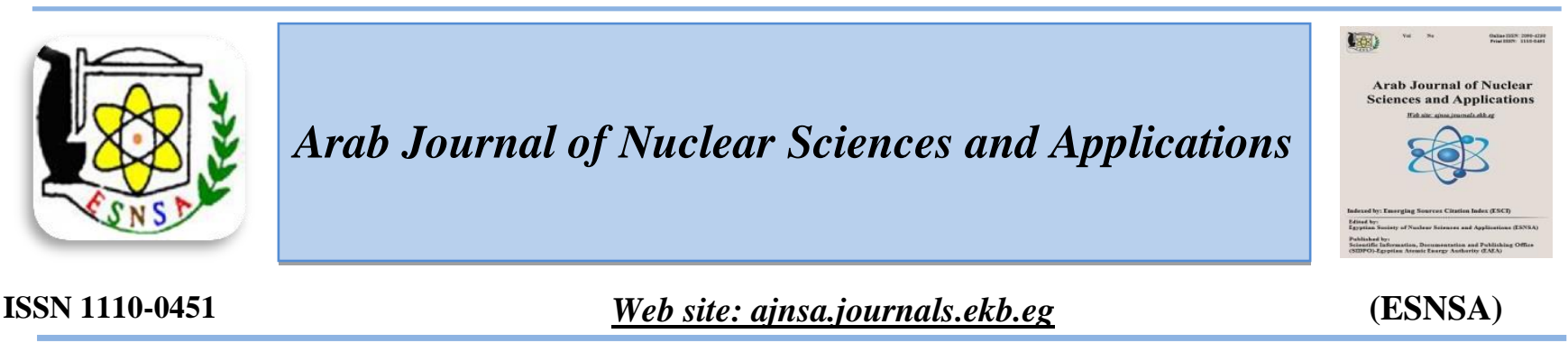

\title{
Reduction of Some Extra-Articular Complications Associated with Arthritis Development in Rats by Low Dose $\gamma$-Irradiation
}

\author{
Habiba Abd El-wahab Abd El-Fatah 1*, Magda Kamal Ezz 2, Hanan Ahmed El-Kabany1, Sawsan \\ Mohammed Elsonbaty 3 \\ ${ }^{1}$ Health Radiation Research Department, National Center for Radiation Research \& Technology, Atomic Energy \\ Authority, Cairo, Egypt \\ ${ }^{2}$ Biochemistry Department, Faculty of Science, Ain shams University, Cairo, Egypt 3 Radiation microbiology \\ ${ }^{3}$ Department, National Center for Radiation Research \& Technology, Atomic Energy Authority, Cairo, Egypt
}

\begin{abstract}
Received 23 ${ }^{\text {th }}$ Apr. 2019 Accepted 22 ${ }^{\text {nd }}$ Dec. 2019
\end{abstract}

\section{Introduction}

Rheumatoid arthritis (RA) is a chronic autoimmune inflammatory disease that affects the physical and psychosocial wellbeing of patients and is a major cause of work disability [1]. It affects principally the joints and is usually accompanied by one or more of extra-articular manifestations [2]. Rheumatoid arthritis has several potentially life-threatening extra-articular complications. It is often associated with inflammation in other organs and tissues [3, 4].
Comorbid diseases are the medical conditions associated with RA. The mechanisms of this association may be due to the pathogenesis of RA itself, the effects of medications used for treating $\mathrm{RA}$, or only a coincidence. The continuous systemic inflammation and immune dysfunction characteristic for RA plays a critical role in the development and acceleration of comorbidities [5, 6]. Low-dose radiation (LDR) modulates a variety of immune responses that have exhibited the properties of immune hormesis. LDR has been

Corresponding author: Habibamaster2011@gmail.com

DOI: 10.21608/ajnsa.2019.12214.1209

(C) Scientific Information, Documentation and Publishing Office (SIDPO)-EAEA 
used clinically for the treatment of autoimmune diseases [7]. Several molecular mechanisms and cellular components contribute to the clinical efficacy of low dose radiotherapy (LD-RT). A large body of evidence indicated that low-dose (single dose $\leq 1.0 \mathrm{~Gy}$ ) irradiation predominantly induced anti-inflammatory activation of macrophages $[8,9]$. Despite the known efficacy of low dose radiotherapy in RA treament, irradiation regimens are still not well established. Also, the role of ionizing radiation in treatment of comorbid diseases associated with RA is still unknown. Therefore, further research efforts using a new irradiation protocol are needed to elucidate this role. Rat adjuvant arthritis is an experimental model of polyarthritis which has been widely used for preclinical testing of numerous anti-arthritic agents which are either under preclinical or clinical investigation or are currently used as therapeutics in this disease [10].

\section{Materials and Methods}

\subsection{Experimental animals}

Forty female Wister albino rats with an initial weight of $180 \pm 20 \mathrm{~g}$ were used for the present study. Animals were obtained from the animal breeding unit of the National Center for Radiation Research and Technology (NCRRT), The Atomic Energy Authority, Cairo, Egypt. They were maintained under appropriate conditions of a good ventilation, atmospheric temperature $\left(22 \pm 4^{\circ} \mathrm{C}\right)$, average humidity $(50 \pm 4 \%)$ and a $12 / 12 \mathrm{~h}$ light/dark cycles along the experimental period. The animals were allowed free access to water and were fed a standard rodent pellet diet, containing all necessary nutritive elements. Rats were kept for about one week before the start of the experiment to acclimatize laboratory conditions. All animal procedures adopted in this study were in accordance with the recommendations for the proper care and use of laboratory animals approved by the Ethics Committee of the NCRRT, Cairo, Egypt.

\subsection{Adjuvant induced arthritis (AIA) model} According to the method described by Holoshitz et al. [11], rats were injected subcutaneously with a single dose of $0.1 \mathrm{ml}$ of complete Freund's adjuvant (CFA) (supplied through Sigma-Aldrich,
USA) containing $100 \quad \mu \mathrm{g}$ dry heat-killed Mycobacterium tuberculosis (H37Ra) suspended in mineral oil (Paraffin) into the dorsal root at the base of the tail. The day of adjuvant injection was referred to as day zero.

\subsection{Irradiation}

Whole body gamma irradiation of experimental rats was performed at theNCRRT ,Cairo, Egypt, using the Canadian gamma cell-40 (caesium-137 irradiation unit). Rats were exposed to $\gamma$-radiation with a total dose $1 \mathrm{~Gy}$ which was delivered as fractionated doses $0.25 \mathrm{~Gy}$ per week for 4 weeks. The dose rate was $0.44 \mathrm{~Gy} / \mathrm{min}$ calculated according to the dosimeter department in the NCRRT at the time of the experiment.

\subsection{Experimental design}

Forty female wistar albino rats $(180 \pm 20 \mathrm{~g})$ were equally divided into four main groups of 10 rats each as follows:

A- Adjuvant free groups:

- $\quad$ Normal Control group (NC): Rats daily received $1 \mathrm{ml}$ of distilled water via oral tube till the end of the experiment.

- $\quad$ Irradiated group (IRR): Rats were whole body exposed to a fractionated dose of $\gamma$-radiation at a dose level of $0.25 \mathrm{~Gy}$, four times at the $15 \mathrm{th}$, 23th, 30th and 37th days of the experiment up to a total dose of $1 \mathrm{~Gy}$ and received $1 \mathrm{ml}$ of distilled water via oral gavage for 30 consecutive days starting from the 15th day of the experiment

\section{B- $\quad$ Adjuvant induced groups:}

- $\quad$ Arthritic group (AR): Rats were injected subcutaneously with a single dose of $0.1 \mathrm{ml}$ of complete Freund's adjuvant (CFA) containing 100 $\mu \mathrm{g}$ dry Mycobacterium tuberculosis into the dorsal root of the tail. Also, they orally received $1 \mathrm{ml}$ of distilled water for 30 consecutive days starting from the 15th day of the experiment. The day of adjuvant injection is referred to as day zero.

- $\quad$ Arthritic irradiated group (AR+IRR): Rats were inoculated by adjuvant inducer (CFA) as described in group IV. Starting from the 15th day, each arthritic rat orally received $1 \mathrm{ml}$ of distilled water for 30 consecutive days and was exposed to a whole body gamma radiation as in group III on the 15th, 23th, 30th and 37th days following CFA inoculation.

At the end of the experiment, after an overnight fast, all experimental rats were anesthetized with diethyl ether and immediately whole blood samples were withdrawn from each rat by heart 
puncture. Each blood sample was divided into two parts; the first part was allowed to clot at $37 \mathrm{oC}$ for $15 \mathrm{~min}$ in a plain tube. The clotted blood was then centrifuged at 4,000 rpm for $10 \mathrm{~min}$. The separated serum was used for the assessment of alanine aminotransferase (ALT), aspartate aminotransferase (AST) activities and creatinine levels while the other part of blood sample was taken on a tube contains di-sodium ethylenediaminetetraacetic acid (EDTA) for total leukocytic count (TLC).

\subsection{Biochemical measurements}

- $\quad$ Assessment of liver enzymes

The activities of alanine aminotransferase (ALT) and aspartate aminotransferase (AST) were assayed in serum by the kinetic method using a commercial kit (Linear, Spain) according to the method described by Winn-Deen et al. [12].

\section{- Kidney function test}

The concentration of creatinine was determined by the kinetic colorimetric method using available commercial kit (Linear, Spain) according to the method described by Bartels and Böhmer [13].

- Assessment of inflammatory responses

Total leukocytic count (TLC) was performed using the hemocytometer according to the method described by Turgeon [14].

2.6. Statistical analysis

Statistical analysis of results including the mean, standard error (SE) and $\mathrm{p}$ values was performed using GraphPad prism (version 5.01) for windows. Data were analyzed using one-way analysis of variance (ANOVA) followed by Tukey-Kramer multiple comparison test for comparison means of different groups. The data were expressed as mean \pm standard error. Differences were considered statistically significant at $\mathrm{P} \leq 0.05$, highly significant at $\mathrm{P} \leq 0.01$ and very highly significant at $\mathrm{P} \leq 0.001$.

\section{RESULTS}

\subsection{Liver function tests}

Alanine aminotransferase (ALT) and Aspartate Aminotransferase (AST)

The results are illustrated in Figures (1\&2). The experimental data obtained from the control group revealed that the mean value of serum ALT and AST activities were $25.43 \pm 0.96 \mathrm{U} / \mathrm{L}$ and $44.18 \pm$ $2.69 \mathrm{U} / \mathrm{L}$, respectively. The results obtained in the present study revealed that subcutaneous injection of CFA into the dorsal root at the base of tail of the experimental rats produced a significant increase $(\mathrm{P} \leq 0.001)$ in the ALT \& AST activities by $68.62 \%$ and $63.81 \%$, respectively in comparison with the control group. On the other hand, the whole body $\gamma$-irradiation of the experimental arthritic rats with $0.25 \mathrm{~Gy} / \mathrm{Week}$ for four weeks revealed a significant decrease $(\mathrm{P} \leq 0.001)$ in serum ALT \& AST activities by $31.44 \%$ and $34.66 \%$, respectively in comparison with arthritic untreated group.

\subsection{Creatinine level}

The results are graphically illustrated in Figure (3). The experimental data obtained from the control group revealed that the mean value of serum creatinine concentration was $0.44 \pm 0.03 \mathrm{mg} / \mathrm{dl}$. The results for healthy rats exposed to whole body $\gamma$-radiation (0.25 Gy/Week for four weeks) revealed no significant changes in serum creatinine concentration compared to the control group value. Data revealed that subcutaneous injection of CFA into the dorsal root of tail of the experimental rats induced renal toxicity as evidenced by the significant sharp increase $(\mathrm{P} \leq 0.001)$ in serum creatinine level by $72.73 \%$, in comparison with control values. Treatment of the experimental arthritic rats with low dose $\gamma$-irradiation revealed a significant decrease at $(\mathrm{P} \leq 0.01)$ in the elevated serum creatinine concentration by $26.32 \%$ in comparison with arthritic untreated group.

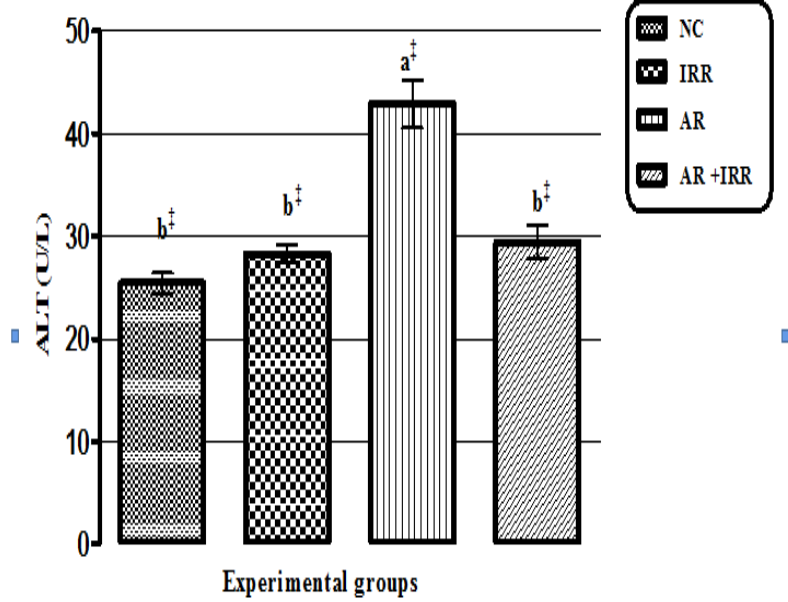

Fig. (1): ALT activities in serum of different animal groups. at, bł denote significant change at $(\mathrm{P} \leq$ 0.001 ) versus control and arthritic groups, respectively 


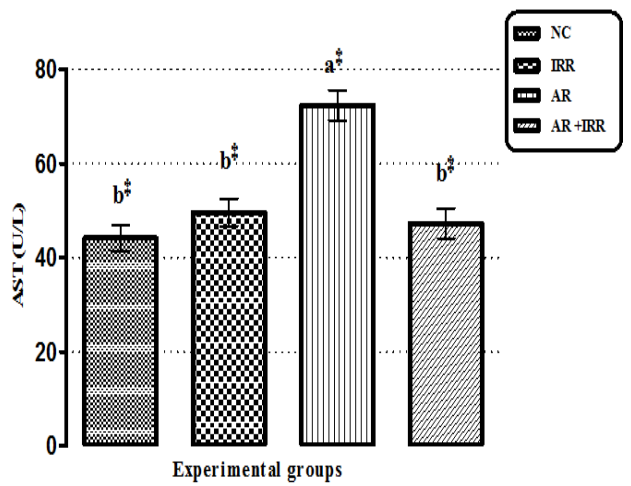

Fig. (2): AST activities in serum of different animal groups. ał, bł denote significant change at $(\mathrm{P} \leq 0.001)$ versus control and arthritic groups, respectively

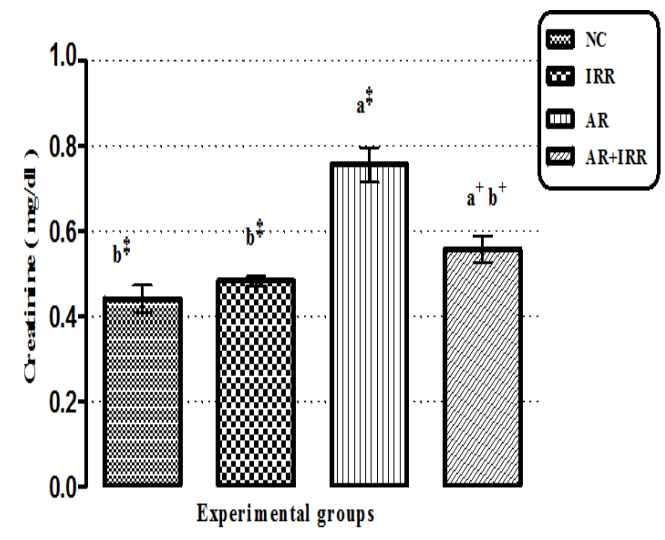

Fig. (3): Creatinine levels in serum of different animal groups. $a+, b+$ denote significant change at $(\mathrm{P} \leq 0.01)$ versus control and arthritic groups, respectively. a + b $\ddagger$ denote significant change at $(\mathrm{P} \leq 0.001)$ versus control and arthritic groups, respectively

\subsection{Inflammatory responses}

Total leukocytic count (TLC) is illustrated in Figure (4) . The experimental data obtained from the normal control (NC) group showed that the mean value of TLC was $3.81 \pm 0.25\left(10^{3} \mathrm{cell} / \mathrm{mm}^{3}\right.$ blood). The whole body $\gamma$-irradiation of healthy rats with $0.25 \mathrm{~Gy} /$ Week for four weeks produced a slightly significant decrease $(\mathrm{P} \leq 0.05)$ in TLC by $\mathbf{2 0 . 7 3} \%$ in comparison with the normal control values. The results obtained in the present study revealed that subcutaneous injection of CFA into the dorsal root at the base of tail of experimental rats produced a significantly sharp increase $(\mathrm{P} \leq 0.001)$ in TLC by $190.81 \%$ in comparison with the normal control. On the other hand, the whole body $\gamma$-irradiation of the experimental arthritic rats with $0.25 \mathrm{~Gy} /$ Week for four weeks staring from day 15 after CFA inoculation revealed a highly significant reduction $(\mathrm{P} \leq 0.001)$ of elevated TLC by $\mathbf{4 4 . 4 0 \%}$ compared to the arthritic group.
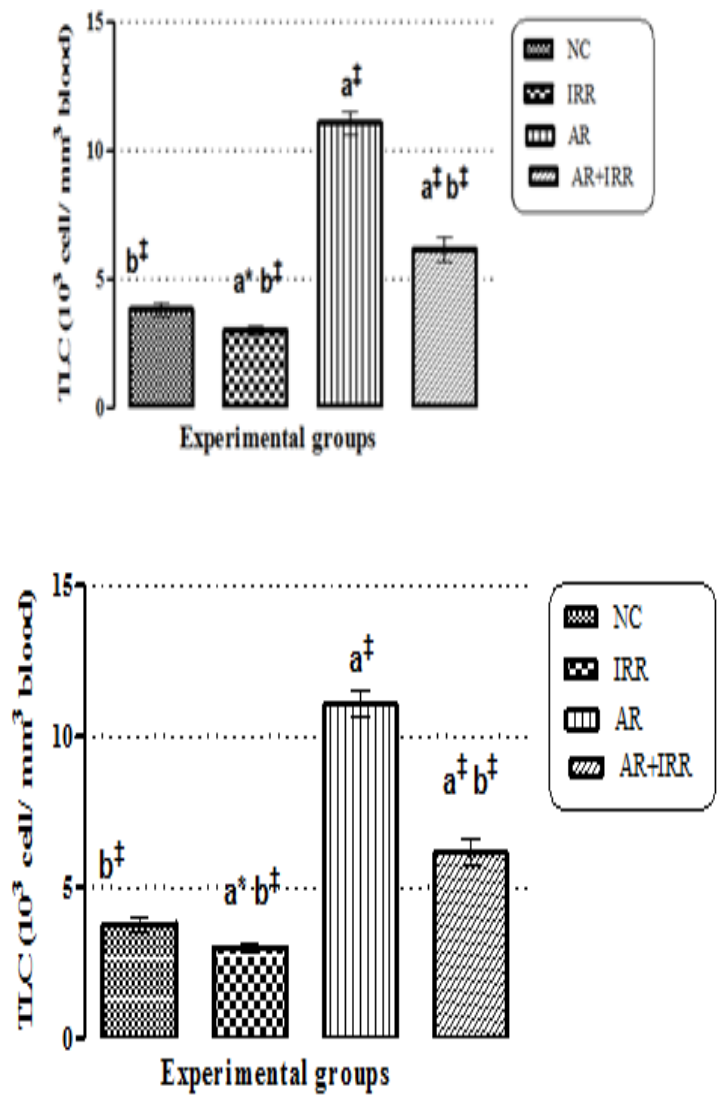

Fig. (4): Total leukocytic count in different animal groups. $\mathbf{a}^{*}$ : significant against normal control at $(\mathrm{P} \leq 0.05), \mathbf{a}^{*}$ : very highly significant against normal control at $(\mathrm{P} \leq 0.001), \mathbf{b}^{\ddagger}$ : very highly significant against arthritic group at $(\mathrm{P} \leq$ $0.001)$

\section{DISCUSSION}

Since RA is an autoimmune disease, it can affect any part of the body and can contribute to the development of a whole plethora of life threating conditions [15]. Adjuvant-induced arthritis (AIA) in rats is considered a model of chronic inflammation that is similar to RA in human. This model mirrors much of the pathology of RA; including hyperplasia of the synovial tissues, inflammatory infiltration of the joints, and destruction of bone and cartilage in the synovial joint $[16,17]$. 
To study the systemic effects of RA on liver, the activity of liver enzymes in serum was assayed. In the current study, subcutaneous injection of CFA into rats induced a marked rise in liver marker enzymes, a finding that is in harmony with previous studies of Kshirsagar et al. [18] and Mbiantcha et al. [19] that reported, a significant rise in the serum activities of AST and ALT in the arthritic control group after injection of CFA into rats compared to normal control rats. Also, Banji et al. [20] demonstrated that liver impairment is a typical feature in adjuvant arthritis when they assessed liver injury in adjuvant induced arthritis by ascertaining the serum activities of ALT and AST. The marked elevation in the serum activities of ALT and AST in arthritic rats might be due to injury of the architecture of hepatic cells resulting in leaching of these enzymes from the damaged cells of the liver into the circulation [20]. This injury of hepatic cells might be attributed to free radical-mediated lipid peroxidation of liver cell membrane. Free radicals were found to be produced in large quantities at the site of inflammation [21]. Similarly, CFA injection into rats causes a significant release of these reactive oxgen species [22]. On the other hand, the present results results revealed that exposure of arthritic rats to a low dose of $\gamma$-radiation reduced the elevated activities of ALT and AST and resulting in a significant improvement as compared to arthritic untreated rats. This data is in accordance with a pervious study of Rashed et al. [23] that reported a significant reduction in the elevated serum activities of ALT and AST after being exposed to a low dose of $\gamma$-irradiation. The current data also agree with Moustafa et al. [24] who reported that a low dose of radiation (LDR) possess hepatoprotective activity and restored tissue vitality in liver induced damage model in rats. Moreover, a low-dose of $\gamma$-irradiation was found to induce an endogenous antioxidant defense in the liver which could be beneficial in protecting the liver cells from oxidative stress [25, 23].

To determine the systemic effects of RA as well as the possible effects of the proposed treatment agent on the kidney, serum creatinine level was determined in the present study since it is the most commonly used parameter for renal excretory function [26]. The present results showed that subcutaneous injection of CFA into rats induced renal toxicity as evidenced by a significant sharp increase in serum creatinine level as compared to normal control values. These results agree with Ekambaram et al. [27] who found an increase in serum creatinine levels in adjuvant induced arthritic rats when compared with the normal control group which indicates the kidney dysfunction in arthritic rats. Similarly, Ramadan and EL-menshawy [28] also reported that serum creatinine levels were significantly increased in the adjuvant induced arthritis group compared to the control group. Addionally, Filho et al. [29] also reported an alteration and impairment in kidney function in arthritic rats. Under normal condition, oxidative stress is just kept at low level and unharmful to the kidney [30]. CFA injection into rat causes a significant release of ROS as mentioned by Cascão et al. [22]. Accordingly, the increase in creatinine level in arthritic rats might be attributed to an increase of renal oxidative stress due to up-regulation of ROS production and down-regulation of the antioxidants expressions [31].

On the other hand, the present results showed that treatment of arthritic rats with a low dose of $\gamma$-irradiation revealed a significant decrease in the the elevated serum creatinine concentration in comparison with arthritic untreated group. However, the exact mechanism, by which a low dose of $\gamma$-irradiation causes this reduction in the elevated creatinine concentration in adjuvant induced arthritic rat model, is still unknown, it has been reported by Aunapuu et al. [32] that a low dose of irradiation causes a reduction in the elevated serum creatinine levels in renal injury model in rats. Furthermore, it was found that LDR significantly prevents renal damage and dysfunction in diabetic rats through attenuation of inflammation and oxidative stress by activation of the Akt signaling pathway and upregulation of multiple renal antioxidant levels that mediated by nuclear factor E2-related factor-2 (Nrf-2) expression in the kidney [33, 34, 30]. The latter is a key transcription factor that regulates intracellular redox balance and is a sensor of oxidative stress and it positively regulates the expression of several downstream genes (SOD-1, NQO-1 and HO-1) playing an important role in the prevention of oxidative stress and damage $[35,30]$. These genes are up-regulated through the antioxidant response regulatory element in response to oxidative stress [36]. 
Regarding inflammatory responses, leukocytes (white blood cells) are the major cellular elements of the immune system that comprise different lineages of lymphocytes (B and $\mathrm{T}$ cells) as members of an antigen-specific effector response, as well as polymorphonuclear (PMN) and mononuclear cells (MC) as components of the innate immune system [37]. The present results showed that subcutaneous injection of CFA into rats produced a significant sharp increase in total leukocytic count (TLC) as compared to normal control. This finding is in accordance with pervious observations reported by Ekambaram et al. [27] who found changes in many hematological parameters in CFA-induced arthritic rats such as sharp increase in white blood cells (WBC) count when compared with the control rats. Additionally, Glenn et al. [38] reported leukocytosis (increase in the number of leukocytes) on day 21 postinduction of arthritis. More to the point, Franch et al. [39] found leukocytosis with a high percentage of neutrophils (neutrophilia) and a high number of lymphocytes. The authors also observed a marked increase in the number of both CD4+ and CD8+ Tcells in arthritic rats, but the rise in CD8+ T-cells was more pronounced than the increase in CD4+ T-cells. They suggested that these fluctuations in white blood cells are probably secondary to the inflammatory process present in adjuvant arthritis. The significant increase in TLC in adjuvantinduced arthritic rats in the present investigation might be attributed to an increase in CD8+ (Tcells) subset that carry specific receptors which recognise mycobacterial determinants present in CFA preparation as suggested by Raulet [40] and Born et al. [41]. Also, the increase in CD4+ (Tcells) subset may be another factor for the elevated TLC since the number of CD4+ T-cells has been shown to increase in human RA [42]. Moreover, it has been dmonestrated that the rise in TLC in arthritic condition may be due to release of IL-1 $\beta$ inflammatory response which increases the production of both granulocyte and macrophages colony stimulating factor [43].

On the other hand, exposure of arthritic rats to a low dose of $\gamma$-radiation caused a highly significant reduction in the elevated TLC as compared to arthritic untreated group. This finding agrees with Bogdándi et al. [44] who reported that a low dose of irradiation caused quantitative alterations in the numbers of leukocytes.
Additionally, Tsukimoto et al. [45] found a reduction of $\mathrm{CD} 8+(\mathrm{T}$-cells) subset after repeated irradiation with $0.5 \mathrm{~Gy} /$ week for 4 weeks in an animal model of autoimmune disease. In rheumatoid arthritis, the inflammatory infiltrate in the synovia consists of activated fibroblasts, monocytes and lymphocytes, which show histochemical signs of dysregulation of apoptosis [46]. Induction of apoptosis or necrosis of these activated inflammatory cells by ionizing irradiation might theoretically be a successful way to control the activity of this destructive disease. In adjuvant induced arthritis, such efficacy has been suggested by Trott et al. [47] and Hildebrandt et al. [48]. Beside its central role in cellular homeostasis, apoptosis significantly impacts on immune regulation and radiation response. In line with that, Voll et al. [49] reported that a low dose radiotherapy produced its anti-infllammatory effect by sending an immunosuppressive signal, which is received by the thrombospondin receptor (CD36) on activated leukocytes (mononuclear cells) resulting in down-regulation of pro-inflammatory cytokines (TNF- $\alpha$ and IL-1) and up-regulation of the anti-inflammatory cytokine IL-10. Kern et al. [50] also reported a dose-dependent induction of apoptosis in leukocytes (mononuclear cells) after a low dose radiotherapy at a single dose rate of 0.3 and $0.7 \mathrm{~Gy}$ and suggested that this response may be a contributing factor to the overall antiinflammatory effect induced by low doses of radiation. This mechanism has gained much support in many other studies $[51,52,53,54]$. The current results revealed a slight decrease in TLC after whole body $\gamma$-irradiation of healthy rats as compared to the normal control values despite its role in improving other inflammatory and arthritic parameter and improving the disease state in arthritic rats. This observation is in accordance with Park and Lee [55] who reported that using low radiation doses for treatment of inflammatory disorders had minimal side effects on most normal tissues, thus the risks of radiation exposure always have to be weighed against the therapeutic benefits. The authors also mentioned that low dose radiotherapy for these disorders may be safely and effectively used, especially in older patients who are reluctant to use other treatment options. Therefore, this reduction in TLC by irradiation cannot be described as diseased state comparing with its benefits. 


\section{CONCLUSION}

The current investigation demonstrates that a low dose of $\gamma$-irradiation at the specified dose level of $0.25 \mathrm{Gyx} 4$ has a positive effect upon already-established arthritis in rats. It normalized the haematological and biochemical abnormalities occurred after induction of arthritis and reduce the extra-articular complications occurred in the liver and kidney. Further histopathological, radiological and molecular studies are needed to elucidate in detail precise mechanisms for these outcomes.

\section{REFERENCES}

(1) Omorogbe O, Ajayi AM, Ben-Azu B, Oghwere EE, Adebesin A, Aderibigbe AO, Okubena O and Umukoro S (2018): Jobelyn $^{\circledR}$ attenuates inflammatory responses and neurobehavioural deficits associated with complete Freund-adjuvantinduced arthritis in mice. Biomedicine \& pharmacotherapy. 98:585-593.

(2) Firestein GS (2008): Kelley's textbook of rheumatology: Saunders, Elsevier; 2008.

(3) Ramiro S, Machado P, Singh JA, Landewé RB and da Silva JAP (2010): Applying science in practice: the optimization of biological therapy in rheumatoid arthritis. Arthritis research \& therapy; 12(6): 220.

(4) Surapneni KM and Gopan VSC (2008): Lipid peroxidation and antioxidant status in patients with rheumatoid arthritis. Indian J. Clin. Biochem., 23(1): 41-44.

(5) Osiri M and Sattayasomboon Y (2013): Prevalence and out-patient medical costs of comorbid conditions in patients with rheumatoid arthritis. Joint Bone Spine. 80(6):608-612.

(6) Gabriel SE (2008): Why do people with rheumatoid arthritis still die prematurely? Annals of the rheumatic diseases. 67(3):iii30-34.

(7) Cui J, Yang G, Pan Z, ZhaoY, Liang X, Li $\mathrm{W}$ and Cai L (2017): Hormetic response to low-dose radiation: Focus on the immune system and its clinical implications. International journal of molecular sciences.18(2):280.

(8) Rödel F, Keilholz L, Herrmann M, Sauer $R$ and Hildebrandt G (2007): Radiobiological mechanisms in inflammatory diseases of low-dose radiation therapy. International journal of radiation biology. 83(6):357-366.

(9) Gough MJ, Young K and Crittenden M (2013): The impact of the myeloid response to radiation therapy. Clinical \& developmental 2013(281958):1-14.

(10) Stills HF Jr (2005): Adjuvants and antibody production: dispelling the myths associated with Freund's complete and other adjuvants. Journal of the institute for laboratory animal research (ILAR). 46(3):280-293.

(11) Holoshitz J, Matitiau A and Cohen IR (1984): Arthritis induced in rats by cloned $\mathrm{T}$ lymphocytes responsive to mycobacteria but not to collagen type II. The journal of clinical investigation. 73(1):211-215.

(12) Winn-Deen ES, David H, Sigler G and Chavez R (1988): Development of a direct assay for alpha-amylase.Clinical chemistry. 34(10):2005-2008.

(13) Bartels H and Böhmer M (1971): Microdetermination of creatinine. Clinical chimica acta. 32(1):81-85.

(14) Turgeon ML (1999): Clinical hematology: Theories and procedures, $3^{\text {rd }}$ ed, pp: $320-$ 321.

(15) Zelman D (2012): Rheumatoid Arthritis (RA) Complications. WebMD, 2012. Available at: http://www.webmd.com/ rheumatoid-arthritis/guide/ rheumatoidarthritis-complications. Accessed: 7 April 2012.

(16) Billingham MEJ (1990): Models of arthritis and the search for anti-arthritic drugs. In: Orme $\mathrm{M}$, ed. Anti-rheumatic drugs. New York: Pergamon, pp: 1-47.

(17) Chou LW, Wang J, Chang PL and Hsieh YL (2011): Hyaluronan modulates accumulation of hypoxiainducible factor-1 alpha, inducible nitric oxide synthase, and matrix metalloproteinase- 3 in the synovium of rat adjuvant-induced arthritis model. Arthritis research \& therapy. 13(3):R90.

(18) Kshirsagar AD, Panchal PV, Harle UN, Nanda RK and Shaikh HM (2014): AntiInflammatory and antiarthritic activity of anthraquinone derivatives in rodents. International journal of inflammation. 2014(690596):1-12. 
(19) Mbiantcha M, Almas J, Shabana SU, Nida D and Aisha F (2017): Anti-arthritic property of crude extracts of Piptadeniastrum africanum (Mimosaceae) in complete Freund's adjuvant-induced arthritis in rats. BMC complementary and alternative medicine. 17(111):1-16.

(20) Banji D, Pinnapureddy J, Banji OJ, Saidulu A and Hayath MS (2011): Synergistic activity of curcumin with methotrexate in ameliorating Freund's complete adjuvant induced arthritis with reduced hepatotoxicity in experimental animals. European journal of pharmacology. 668(1-2):293-298.

(21) Gotia S, Popovici I and Hermeziu B (2001): Antioxidant enzymes levels in children with juvenile rheumatoid arthritis. Revista medico-chirurgicala a societatii de medici si naturalisti din Iasi. 105(3):499 503.

(22) Cascão R, Vidal B, Raquel H, NevesCosta A, Figueiredo N, Gupta V, Fonseca JE and Moita LF (2014): Potent antiInflammatory and antiproliferative effects of gambogic Acid in a rat model of antigen-induced arthritis. Mediators of inflammation. 2014(195327):7.

(23) Rashed RR, El-Ghazaly MA and Kenawy SA (2014): Protective effect of garlic oil alone or combined with low-dose gamma irradiation on paracetamol-induced hepatotoxicity in rats. European journal of biology and medical science research. 2(3):1-27.

(24) Moustafa EM, Abdel-Rafei MK, Thabet NM and Hasan HF (2015): Moringa oleifera leaf ethanolic extract subsidized by low doses of gamma irradiation modulates the thioacetamide induced fibrotic signs in liver of albino rats. Pakistan journal of zoology. 47(3):793802.

(25) Avti PK, Pathak, CM, Kumar S, Kaushik G, Kaushik T, Farooque A, Khanduja KL and Sharma SC (2005): Low dose gammairradiation differentially modulates antioxidant defense in liver and lungs of Balb/c mice. International journal of radiation biology. 81(12):901-910.

(26) Anders H-J and Vielhauer V (2011): Renal co-morbidity in patients with rheumatic diseases. Arthritis research \& therapy. 13(2):222.

(27) Ekambaram S, Perumal SS and Subramanian V (2010): Evaluation of antiarthritic activity of Strychnos potatorum Linn seeds in Freund's adjuvant induced arthritic rat model. $B M C$ complementary and alternative medicine. 10:56-65.

(28) Ramadan and EL-menshawy (2013): Protective effects of ginger-turmeric rhizomes mixture on joint inflammation, atherogenesis, kidney dysfunction and other complications in a rat model of human rheumatoid arthritis. International journal of rheumatic diseases. 16(2):219229.

(29) Filho PY, Bracht A, Ishii-Iwato EL, Lousano SH, Bracht L and Kelmer-Bracht AM (2003): The urea cycle in the liver of arthritic rats. Molecular and cellular biochemistry. 243(1-2):97-106.

(30) Shao M, Lu X, Cong W, Xing X, Tan Y, $\mathrm{Li}$, Li Y X, Jin L, Wang X, Dong J, Jin S, Zhang C and Cai L (2014): Multiple lowdose radiation prevents type 2 diabetesinduced renal damage through attenuation of dyslipidemia and insulin resistance and subsequent renal inflammation and oxidative stress. PloS one. 9(3):e92574.

(31) Cui W, Li B, Bai Y, Miao X, Chen Q, Sun $\mathrm{W}$, Tan $\mathrm{Y}$, Luo $\mathrm{P}$, Zhang $\mathrm{C}$, Zheng $\mathrm{S}$, Epstein PN, Miao L and Cai L (2013): Potential role for Nrf2 activation in the therapeutic effect of MG132 on diabetic nephropathy in OVE26 diabetic mice. American journal of physiology, endocrinology and metabolism. 304(1):E87-99.

(32) Aunapuu M, Pechter U, Gerskevits E, Marjamfigi MM, Suuroja S, Arend A, Kolts I, Kiilmel W, and Ots M (2004): Low-dose radiation modifies the progression of chronic renal failure. Annals of anatomy-anatomischer anzeiger. 186(3):277-282.

(33) Zhang C, Tan Y, Guo W, Li C, Ji S, Li X and Cai L (2009) Attenuation of diabetesinduced renal dysfunction by multiple exposures to low-dose radiation is associated with the suppression of systemic and renal inflammation. 
American journal of physiology, endocrinology and metabolism. 297(6):E1366-1377.

(34) Xing X, Zhang C, Shao M, Tong Q, Zhang G, Li C, Cheng J, Jin S, Ma J, Wang G, Li $X$ and Cai L (2012) Low-dose radiation activates Akt and Nrf2 in the kidney of diabetic mice: a potential mechanism to prevent diabetic nephropathy. Oxidative medicine and cellular longevity. 2012(291087):1-12.

(35) Adair LS (2008) Child and adolescent obesity: epidemiology and developmental perspectives. Physiology \& behavior. 94(1):8-16.

(36) Tan Y, Ichikawa T, Li J, Si Q, Yang H, Chen X, Goldblatt CS, Meyer CJ, Li X, Cai L and Cui T (2011): Diabetic downregulation of Nrf2 activity via ERK contributes to oxidative stress-induced insulin resistance in cardiac cells in vitro and in vivo. Diabetes. 60(2):625-633.

(37) Kobayashi SD, Voyich JM, Burlak C and Deleo FR (2005): Neutrophils in the innate immune response. Archivum immunologiae et therapiae experimentalis. 53(6):505-517.

(38) Glenn EM, Gray J and Kooyers W (1965): Chemical changes in adjuvant induced polyarthritis of rats. Am J Vet Res. 26(114):1195-203.

(39) Franch A, Castellote C and Castell M (1994): Blood lymphocyte subsets in rats with adjuvant arthritis. Annals of the rheumatic diseases. 53(7):461-466.

(40) Raulet DH (1989): Antigens for $\gamma \delta \mathrm{T}$ cells. Nature.339:342-343.

(41) Born W, Hall L, Dallas A, Boymel J, Young D and O'Brien R (1990): Recognition of a peptide antigen by heat shock reactive T/B $\mathrm{T}$ lymphocytes. Science. 249(4964):67-69.

(42) Veys EM, Hermanns P, Schindler J, Kung PC, Goldstein G, Symoens J, Van Wauwe J (1982): Evaluation of T cell subsets with monoclonal antibodies in patients with rheumatoid arthritis. The journal of rheumatology. 9(1):25-29.

(43) William JK (1996): Arthritis and allied condition, a textbook of rheumatology, $3^{\text {rd }}$ ed, volume 1, Waverly company, Baltimore, Md, USA.
(44) Bogdándi EN, Balogh A, Felgyinszki N, Szatimári T, Persa E, Hildebrandt G, Sáfrány G and Lumniczky K (2010): Effect of low-dose radiation on the immune system of mice after total-body irradiation. Radiation research. 174(4):480-489.

(45) Tsukimoto M, Nakatsukasa H, Sugawara, K, Yamashita K and Kojima S (2008): Repeated 0.5-Gy gamma irradiation attenuates experimental autoimmune encephalomyelitis with up-regulation of regulatory T cells and suppression of IL17 production. Radiation research. 170(4):429-436.

(46) Chou CT, Yang JS and Lee MR (2001): Apoptosis in rheumatoid arthritis expression of Fas, Fas-L, p53, and Bcl-2 in rheumatoid synovial tissues. The journal of pathology. 193(1):110-116.

(47) Trott KR, Parker R and Seed MP (1995): The effect of X-rays on experimental arthritis in rat. Strahlentherapie und onkologie. 171(9):534-538.

(48) Hildebrandt G, Radlingmayr A, Rosenthal S, Rothe R, Jahns J, Hindemith M, Rödel F and Kamprad F (2003): Low-dose radiotherapy (LD-RT) and the modulation of iNOS expression in adjuvant-induced arthritis in rats. International journal of radiation biology. 79(12):993-1001.

(49) Voll RE, Herrmann M, Roth EA, Stach C, Kalden JR and Girkontaite I (1997): Immunosuppressive effects of apoptotic cells. Nature. 390(6658):350-351.

(50) Kern P, Keilholz L, Forster C, Seegenschmiedt $\mathrm{MH}$, Sauer $\mathrm{R}$ and Herrmann M (1999): In vitro apoptosis in peripheral blood mononuclear cells induced by low-dose radiotherapy displays a discontinuous dose-dependence. International journal of radiation biology. 75(8):995-1003.

(51) Huynh MLN, Fadok VA and Henson PM (2002): Phosphatidylserine-dependent ingestion of apoptotic cells promotes TGF$\beta 1$ secretion and the resolution of inflammation. The journal of clinical investigation. 109(1):41-50.

(52) Ren Y, Xie Y, Jiang G, Fan J, Yeung J, Li W, Tam PK and Savill J (2008): Apoptotic cells protect mice against 
lipopolysaccharide-induced shock.

Journal of immunology. 180(7):49784985.

(53) Perruche S, Saas P and Chen W (2009): A poptotic cell-mediated suppression of streptococcal cell wall-induced arthritis is associated with alteration of macrophage function and local regulatory T-cell increase: a potential cell-based therapy? Arthritis research \& therapy. 11(4):R104.

(54) Esmann L, Idel C, Sarkar A, Hellberg L, Behnen M, Möller S, van Zandbergen G, Klinger M, Köhl J, Bussmeyer U, Solbach W and Laskay T (2010): Phagocytosis of apoptotic cells by neutrophil granulocytes: Diminished proinflammatory neutrophil functions in the presence of apoptotic cells. Journal of immunology. 184(1):391400.

(55) Park SH and Lee JE (2017): Radiotherapy, a new treatment option for non-malignant disorders: Radiobiological mechanisms, clinical applications, and radiation risk. Journal of rheumatic diseases. 24(2):74-84. 